\title{
The Knowledge Exchange Framework: understanding parameters and the capacity for transformative Engagement
}

\author{
Dr Matthew Johnson ${ }^{1}$
}

This is an Author's Original Manuscript (AOM) of an article published by Taylor \& Francis in Studies in Higher Education.

\begin{abstract}
The UK Conservative Government 2017-2019 has taken steps to promote Engagement as a means of Knowledge Exchange (KE). In 2019/2020, a Knowledge Exchange Framework (KEF) will be introduced alongside the existing Research (REF) and Teaching (TEF) evaluations. Indeed, the OfS (Office for Students) and UKRI (UK Research and Innovation) $(2018,1)$ regard each of these evaluations as 'mutually reinforcing'. Given that the KEF is likely to take place in full for the first time in 2020, it is essential that colleagues understand both the nature of the Engagement agenda, the reasons for its emergence, the possibilities it offers and means by which to reduce opportunity cost. In this article, I draw upon a range of resources to present a clear overview of these factors and argue that KEF can be harnessed effectively for a number of, often socially valuable, ends and that its most onerous implications can be mitigated efficiently.
\end{abstract}

Keywords: Engagement; Impact; KEF; Knowledge Exchange; Higher Education

In recent years, the UK Higher Education (HE) sector has been subject to a range of agendas and initiatives aimed at addressing issues that, historically, were not regarded as core academic business. Whether it be Widening Participation (WP), Employability or Impact or some other, often overlapping, concept, academia has been tasked to address broader social ills associated with the consequences of neoliberal reform. The simultaneous expansion of the sector and the decline in state investment in the economy has created a context in which Government has sought to delegate responsibility to HE for dealing with issues that it itself is reluctant directly to address. As the elision of WP and recruitment illustrates, this has given the UK sector a character and discourse at odds with its counterparts overseas. The latest agenda to emerge has been Engagement. Stemming from Jo Johnson's wish as Education Secretary to understand the contribution of academia to business - one that reveals a narrow instrumental evaluation of the value of $\mathrm{HE}$-, steps have been taken to map and assess Engagement as a means of Knowledge Exchange (KE). Despite Johnson's having resigned from Office twice, the agenda shows no sign of disappearing, with a Knowledge Exchange Framework (KEF) due to complement the existing Research (REF) and Teaching (TEF) evaluations. Indeed, the OfS and UKRI (Office for Students) and UKRI (UK Research and Innovation) $(2018,1)$ regard each of these evaluations as 'mutually reinforcing'.

Given that the KEF is to take place in full for the first time in 2020, it is essential that colleagues understand both the nature of the Engagement agenda, the reasons for its emergence and the possibilities it offers. This is particularly true in my own discipline, Politics/International Relations (IR), and other non-vocational subjects, since these are areas that are likely to require greater amounts of planning and forethought in order to compensate for the relative lack of commercial exploitation and large grant acquisition in comparison to

\footnotetext{
${ }^{1}$ Matthew Thomas Johnson, PhD, Senior Lecturer in Politics, Lancaster University. Politics, Philosophy and Religion, County South, Lancaster University, Lancaster, United Kingdom, LA1 4YL. ORCID ID: 0000-00029987-7050. m.johnson@lancs.ac.uk
} 
the natural sciences. In what follows, I draw upon a wide body of literature produced by actors involved in development of KEF to provide an account of its functioning. I build upon Jan Selby's (2018) work on the possibilities offered by the Impact agenda to argue that KEF can be harnessed effectively for a number of, often socially valuable, ends and that its most onerous implications can be mitigated efficiently. While my account is more amoral than Selby's by virtue of its concern for colleagues' instrumental reasons for Engagement, this stems from appreciation of the various professional constraints within which colleagues operate. The one core ethical implication of the approach is that colleagues have every reason to engage with agendas in order to ensure that issues and activities perceived to be of critical social value are incorporated into institutional conceptualization of those agendas. The illustrations I introduce are grounded in Politics/IR as a broad subject area, but can serve to illuminate possibilities in other non-vocational disciplines. I begin by outlining a set of literatures on the topic.

\section{Literature review}

Because the KEF is a new evaluation and because the conceptualisation of Engagement in relation to it lies mainly in Governmental and sectoral documentation, the academic literature on Engagement as a phenomenon particular to the UK HE context is sparse. Although Watermeyer and Lewis (2018) and others outline the ways in which the sector is grappling with 'Public Engagement', there is no substantive literature on Engagement as relating to KEF. As such, Codifying and clarifying Engagement through thematic analysis of Governmental and sectoral material is the first key contribution of this article below. However, there are broader literatures on the motivation for $\mathrm{HE}$ as a sector to contribute to social goods, on the administrative motivation for development of evaluative frameworks and on the concept, such as Impact, as related to Engagement.

A broad range of scholars have highlighted the conflict between public concern for public goods and the reluctance of government to supply those goods within a free market society (for example, Ishkanian and Glasius 2018; Berry 2014). For electoral reasons, where there is reluctance in government to intervene directly, political parties often delegate responsibility to non-governmental organizations for fulfilment of the public's wishes (see Watermeyer and Lewis 2018, 1613). Support for business through dissemination of expert knowledge is one such example (see De Boer, Enders, and Schimank 2007). Businesses require skilled workers and academic consultation for profitability. In the absence of direct state provision of those goods, there has been a shift from HE as a public good (see Collini 2012) to a secondary justification for $\mathrm{HE}$ as a provider of public goods beyond formal education (Johnson, et al. 2019). This expansion of 'core business' through Governmental delegation of responsibility for public goods is evident in other professions. After a decade of austerity, we see Police Officers performing tasks previously restricted to Social Workers, GPs serving as gatekeepers to the Welfare System (see Johnson, Degerman and Geyer 2019) and now academics acting as Careers Advisors (see Johnson 2016).

Government concern for HE's contribution to society has already been evident in the 'Impact agenda'. The agenda operates on the understanding that, aside from any intrinsic value in terms of knowledge, academic work ought to impact publics beyond academia (see Watermeyer and Lewis 2018, 1613). In one sense, this is not new. Read through the lens of modern transformative research methods, Socrates died for his Participatory Action Research (PAR) on wisdom. He engaged with his fellow citizens and a range of experts on an issue of shared concern and had a transformative effect on the public. The research was both high quality and impactful. Today, it may have led to a REF Impact Case Study rather than a death sentence. In the time since, the academy has served communities in myriad ways, providing sources of learning for religious bodies, contributing to the law and, since the 1960s, fostering forms of social mobility via outreach and public engagement schemes, of which the Open 
University's BBC2 programming was an excellent example. Engagement, in a very real sense, is not new. It has always been integral to the profession (see Johnson, et al. 2019). Indeed, Selby (2018) clearly highlights the opportunity that this poses for transformative interventions that improve the lives of those excluded by neoliberal processes. However, he also demonstrates that IR REF Impact Case Studies seldom foster transformative impacts and especially not in an international context. As he $(2018,336)$ puts it, the Case Studies are 'essentially technical or mildly reformist narratives of organic intellectuals helping Western governments and associated intergovernmental organisations to refine their techniques of liberal governance'.

The critical educational literature suggests reasons for this. Watermeyer and Chubb $(2019,1556)$ argue that strategic guidance on REF Impact 'have tended to concentrate on methods for the production of impact and not how it is experienced or evaluated'. They examine the instrumentality of approaches, the fostering of 'gaming' of systems, and the extent to which REF metrics favour those approaches that have economic and health impacts in evaluation and then reward them financially through distribution of Quality Related (QR) funding. In one sense, this may confirm the extent to which neoliberalism reproduces itself by creating evaluative systems that privilege particular values. The public assumption of the need for provision of public goods and the Governmental assertion that HE ought to play a part in that provision presents policy makers with a prima facie reason both to evaluate the success of $\mathrm{HE}$ in that work and to promote further activity through evaluation. REF is a clear example of the audit culture as a central pillar of performance management identified by Shore and Wright (2000) As Sayer (2015, e.g. 1-2) compellingly argues, this culture imposes significant cost in academic time and administrative workload.

In part, this may be explained by the public choice literature, which deploys economic concepts to make sense of political phenomena. For Niskanen (1994), administrators within bureaucracies benefit from permanence and security in their roles that are denied those in the private sector, in particular. Those administrators have a rational self-interest in entrenching their positions by creating ever more elaborate bureaucratic processes that take on an importance as significant as the practical work that those processes seek to manage and building administrative empires that consume resources that cannot easily be reclaimed by those engaged in productive endeavour (academics, in this instance). This is clearly of relevance to the case of REF, TEF and KEF. This account may explain Ginsberg's (2011) dystopian notion of the all administrative university, in which the academy shifts from concern for academic excellence and intrinsic value of knowledge to administrative distinction and corporatisation. Such accounts help both to explain the emergence of the Engagement agenda and KEF and to provide a frame within which to develop strategy to advance departmental and disciplinary interests. Indeed, even if the most pernicious accounts of administration are accurate, they only serve to highlight the need for critical approaches that take Engagement seriously in ways that non-critical approaches take for granted. Counter-intuitively, Selby is surely right to suggest that it is only by adoption of critical approaches that HE can make a genuine impact on the dysfunction fostered by neoliberal reform, even if the Engagement ends up replicating elements of neoliberal discourse and is evaluated in ways that stem from administrative empire building.

\section{Methods}

The research in this article stems from two methods: thematic review of the non-academic literature and practical action research development of Engagement strategy. In order to understand some of the opportunities that this context offers, we need to understand the relationship between Engagement, Knowledge Exchange, Impact and the processes of evaluation. In the absence of an academic literature that takes account of recent developments, 
this can only be achieved through thematic analysis of Governmental and sectoral documentation. To do this, I identified first a set of key actors driving the Engagement agenda in the UK: Government (e.g. OfS, Secretary of State for Education etc.), HE bodies (e.g. UKRI, UUK, Research England, etc.) and profit and non-profit making organizations engaged by Government and HE bodies to advance the Engagement agenda and assist in evaluation of HEI performance (e.g. PraxisAuril, etc.). I conducted an extensive review of key policy statements by each of these actors and identified a set of concepts related to the agenda (Engagement, Knowledge Exchange, Impact) and to the processes of evaluation (KEF, TEF, REF). I then codified the concepts and organised them into a logical order that enables comprehension of the constituent parts of the agenda.

The strategic element of this article is grounded in a practical action research method deployed to 'solve a practical problem' and 'produce guidelines for best practice' (Denscombe 2010, 6). Although Lethwaite and Nind $(2016,413)$ surely have some substance in their desire to move 'focus from individual experiences of research methods teaching to empirical evidence from a study crossing research methods, disciplines and nations', the Engagement agenda is an emerging one that necessarily depends upon innovation. Moreover, although there is substance to Kilburn, Nind and Wiles' $(2014,204)$ desire to foster 'empirical investigation beyond practitioners' reflections on particular courses or of contexts', many of the findings that can be drawn from the existing academic literature depend upon inference for application. This article's contribution to understanding Engagement stems from belief in the value of case study: 'an empirical inquiry that investigates a contemporary phenomenon within its real-life context; when the boundaries between phenomenon and context are not clearly evident; and in which multiple sources of evidence are used' (Yin 1984, 23). The research presented here is an intrinsic case study advanced to understand and explain Engagement research for its own sake (Stake 1995) and in its own context (Mann 2006, 78) through 'worksite' development (see Denscombe 2010,134). I present this account of strategic practice as the basis for colleagues' development of their own approaches to Engagement. The account attempts to demonstrate means of 'Engaging learners in the research process, providing hands-on experience and offering opportunities for critical reflection' which, for Kilburn, Nind and Wiles $(2014,203)$, 'constitute important complementary and overlapping elements of... [a] formally articulated pedagogy'. The research serves, therefore, the needs of those attempting to advance individual and departmental responses to the agenda and associated programmes of evaluation.

It is important to note that 'best practice' will differ according to the strengths of each institution to institution, faculty and department and discipline. The underpinning principle, here, is that action research is more of a strategy than a specific method (Susman and Evered 1978, 589). The research was conducted during development and implementation of departmental strategy by me, as an academics, on my own practice as Departmental Director of Engagement (Edwards and Talbot 1994: 52). The research consists of conceptual analysis of Governmental and sectoral official documents released since 2015. I present a thematic account of the key concepts advanced in those documents in order to achieve clarity in the constituent parts of the Engagement agenda that has led to the KEF. The sections below represent each of those concepts. The strategic approach advanced is threaded through responses to the evidence relating to each of those concepts.

\section{Results}

\section{Engagement and Knowledge Exchange}

Engagement is a core pillar of various universities' strategies to advance their significance (see, for example, Lancaster University 2019). It is increasingly conceived through the lens of the National Co-Ordinating Centre for Public Engagement definition: 
Public engagement describes the myriad of ways in which the activity and benefits of higher education and research can be shared with the public. Engagement is by definition a two-way process, involving interaction and listening, with the goal of generating mutual benefit. (NCCPE 2019)

This includes a wide range of activities with external non-academic communities, most of which relate to engagement in teaching or research. In the context of austerity, stretched public finances and uneven regional growth, Engagement is increasingly presented as an important agenda for leading educational bodies. As the state recedes, universities are often one of few significant economically active public entities in certain areas. Accordingly, the UPP Foundation developed a Civic University Commission to explore the part played by universities in communities and means by which to encourage further action to promote Engagement. The Commission's work led to the Civic University Agreement, to which 30 leading universities subscribed and, in so doing, committed to act as civic bodies (Brabner 2019). The Agreement (see UPP 2019, 9-12), reflects commitment to four areas:

- Understanding local populations, and asking them what they want. Analysis of their place and people's priorities are essential.

- Understanding themselves and what they are able to offer.

- Working with other local anchor institutions, businesses and community organisations to agree where the short, medium and long-term opportunities and problems lie for communities. Linking with local authorities and other local plans, such as the local industrial strategy is particularly important.

- A clear set of priorities. A process of agreeing clear priorities will therefore be necessary and, again, this is where collaboration and aligning resources with local authorities, LEPs (Local Economic Partnerships), NHS bodies and the like can help to identify the live issues that universities can most usefully help with.

The sense of HE Institutions (HEIs) enhancing their contribution to their localities is emphasised by Chris Skidmore (2019), Minister of State for Universities, Science, Research and Innovation, who states that

All our HE institutions can play an important role in addressing the particular economic and social issues facing different local areas. I encourage you to support universities in understanding more about local issues and priorities, and in deploying their intellectual assets for the benefit of people in every part of the country.

It is clear, in this context, that universities are seen increasingly as local and regional anchor institutions precisely because they are enduring and indispensable instruments for development of skills for business and delegation of social goods. Government investment in Engagement lies in the extent to which business recognizes the value of accessible (local), low risk (high quality) and often inexpensive expertise (Reid 2019). Government conceptualizes the value of Engagement through reference to its acting as a pathway for Knowledge Exchange (KE), which is defined in the Higher Education and Research Act 2017 as

in relation to science, technology, humanities or new ideas, means a process or other activity by which knowledge is exchanged where - (a) the knowledge is in, or in connection with, science, technology, humanities or new ideas (as the case may be), and (b) the exchange contributes, or is likely to contribute, (whether directly or 
indirectly) to an economic or social benefit in the United Kingdom or elsewhere. (Higher Education Act 2017, Section 93)

In this respect,

Knowledge Exchange, or Knowledge Transfer, is a key output of academic research. It conveys how knowledge and ideas move between the knowledge source and the potential users of that knowledge. It may occur through the training of postgraduate researchers who subsequently apply that knowledge in the public or private sector, or through direct engagement between the academics and public/private sector via collaborative or contract research, or through the exploitation of intellectual property through the creation of start-up companies, or in many other ways. The key common element is that information and expertise is exchanged with businesses, society and/or the economy (Vitae 2019).

Engagement is that $\mathrm{KE}$ activity that is forged through relationships with non-academic actors. There is no explicit meta-ethical means by which 'benefit' is evaluated and, as Selby (2018) indicates, it is to be assumed that there will be significant disagreement between academics as to what constitutes a valuable form of Engagement. At one level, therefore, concern is quantitative. This is apparent in the ways in which KE is seen as that sub-set of engagement activity that is used as the quantitative basis for infrastructure funding allocation from Research England through HEIF (Higher Education Innovation Fund). Indeed, by virtue of the Civic University Agreement, the sector is committed to more Engagement specifically through the KEF.

\section{Examples of Engagement}

Given the variety of terms deployed to capture work with non-academic groups, including 'outreach' and 'impact', it is important to note that Engagement denotes a broader set of activities than might be expected. The external non-academic community includes a range of potential stakeholders including employers, businesses and organisations from all sectors, voluntary sector agencies and community groups, government agencies, NHS, 'arm's length bodies' and local/national government. As noted at the outset, the potential forms and outcomes are broad. As the term is often abstract, the following provides some illustrative examples with regard to the three key areas of academic workload:

\section{Research}

- co-design and co-development of issues of shared concern for academics and nonacademic actors

- co-development of applications for funding

- participatory research

- co-supervision of PhD students

- consultancy, collaborative or contract research or Knowledge Transfer Partnerships (see NCUB 2013)

Teaching (see McFarlane-Dick and Roy 2006; Wilson, Woolger and Dodd 2017)

- co-design and development of modules and programmes

- external provision of guest lectures

- work-based projects, placements and internships

- mentoring by or for HE students in external settings (see Johnson 2016) 
- $\quad$ education for professionals for specific CPD purposes (see Guild HE 2018)

Administration (see GuildHE 2018)

- innovative forms of student recruitment

- expansion of professional networks

- external contribution to strategic development

The wide range of activities transcend disciplines and subject areas and are necessarily realized in radically distinct ways in those disciplines and areas. In each of these areas of work, it is clear that Engagement plays a central role in Knowledge Exchange.

\section{Knowledge Exchange Framework (KEF)}

At present, the Government is seeking to advance $\mathrm{KE}$ or the measurement of $\mathrm{KE}$ in order to address needs identified by the McMillan Group (2016) 'for enhanced reporting and leadership support, the building of staff expertise, and improvement of the evidence base' (Wade 2016). To this end, Research England (along with UUK and PraxisAURIL) is developing KEF (see Research England 2018a) to assess institutional performance. The stated intention of the KEF is

- To provide HEIs with a useful source of information and data on their knowledge exchange (KE) activities, for the purposes of understanding, benchmarking and improving their own performance.

- To provide businesses and other users (and potential users) of HEI knowledge with another source of information, which may increase visibility of potential university partners and their strengths, and contribute to their internal decision making processes. (Research England 2019, 6)

For McAlpine (2019), this is the sector's 'commitment to explore how to integrate more directly the "voice of the user" into the framework', granting 'further insight into how businesses and others feel about their interactions with universities'. There are, clearly, implications with regard to the commercialization and commodification of $\mathrm{KE}$ as a consequence. The voice of the user is not simply the student seeking to enhance labour market value, but the business that seeks support - often at below market rates - in the pursuit of profit. Performance in keeping business happy through KEF returns will, as with REF and TEF, determine some reputational and financial outcomes (see Anderson 2018). The way in which it is measured will, though, differ.

To clarify the basis upon which KEF will be introduced and proceed, Universities UK (2019) engaged in a consultation exercise with HEIs aimed at developing a set of principles. These were codified in the KE Concordat. The eight guiding principles are:

Principle 1. Mission: Knowledge exchange is a recognised part of the overall university strategy. We have a clear understanding of the institutional role and the purpose of KE and whom the intended beneficiaries are.

Principle 2. Policies: We have clear policies on all the types of KE that we undertake and we ensure they are understood by staff, students, collaborators and beneficiaries.

Principle 3. Engagement: We have clear access points, engagement mechanisms and policies developed to suit the needs of a wide range of beneficiaries working with institutions as publicly funded bodies. 
Principle 4. Working effectively: We make sure that our partners and beneficiaries understand the ethical and charitable regulatory environments in which our institution operates and we take steps to maximise the benefit to them within that context.

Principle 5. Capacity building: We ensure that our staff and students are developed and trained appropriately to understand and undertake their roles and responsibilities in the delivery of successful KE.

Principle 6. Recognition and rewards: We recognise the achievements of our staff and students who perform high-quality KE activities.

Principle 7. Continuous improvement: We proactively strive to share best practice with our peers and have established processes for learning from this.

Principle 8. Evaluating success: We undertake regular institutional and collective monitoring and review of our strengthening KE performance using this concordat and through regional, national or international benchmarks to inform the development and execution of a programme of continuous improvement.

These are, clearly, wide-ranging and transformative in intent. They shape the ways in which HEIs advance KE and provide the basis for further revision to understanding of what constitutes core business. Not only are universities committed to providing service to external bodies, they pursue this through internal transformation of workloads and professional foci. At the very least, this seems to call for a significant, substantive reorganization, expansion of administrative roles and the introduction of additional activity into individual academics' working lives. This is being recognized by reconsideration in many institutions of the place of Engagement in promotions criteria and, given the restriction in number of REF Impact Case Studies and collective focus of REF Research Environment narratives, KEF offers a means of recognizing and codifying work for promotions purposes.

Universities UK $(2019,20)$ have provided the following timeline for implementation of the Concordat is as follows:

- Autumn 2019 - HE institutions sign up to KE concordat and non-HEI stakeholders

- commit to support

- Spring 2020 - guidance on self-evaluation and pro-forma for action plans distributed

- Spring 2020 - Independent Panel formed

- Summer 2020 - action plans published by higher education institutions

- Autumn 2020 - feedback to institutions on action plans, assessment of institutional

- engagement and stakeholder support, recommendations for next steps.

While Universities UK $(2020,5)$ summary of consultation on the Concordat reveals widespread support for the principles and overall aims, there is opposition among 53\% of respondents to forced implementation by UUK and GuildHE. In part, this may reflect broader concerns expressed regarding the possibility of undesirable outcomes, including game playing, through self-assessment, whether the model could be delivered in practice and whether it advanced the audit culture noted by Shore and Wright (2000) (Universities UK 2020,7). Indeed, in one clear sense, Engagement is already measured by the Higher Education Business \& Community Interaction (HE-BCI) survey. HE-BCI data returns feed into a formula for future HEIF allocations, which will 'reach $£ 250 \mathrm{~m}$ by 2020 to enhance the capacity of universities 
across England to work with business and to commercialise their research' (Skidmore 2019). There are good reasons to believe that, although the survey is being reviewed (McAlpine 2019), the data measured will remain prominent. This is because of the principles of evaluation presented by Research England:

- Annual - to reflect up-to-date performance, with many existing KE metrics being gathered annually at present.

- Institutional-level - reflecting that the vast majority of existing data are collected at this level, and many types of KE are multidisciplinary. This also reflects our desire for a low-burden exercise.

- Largely metrics-driven - again reflecting our desire for a low-burden exercise, but also to enable comparability across HEIs. However, we recognise that some areas of KE are not well represented by existing metrics and that responsible metric principles should be taken into account. (Research England 2019, 6-7)

Each of these principles speak to the existing framework through which HE-BCI operates. However, it is anticipated that qualitative, as well as quantitative, elements will feature in KEF in order to take account, and emphasise the importance, of the nuances of work conducted in the Arts, Humanities and Social Sciences (see Coates-Ulrichsen 2018, 4; Research England 2018b).

This is apparent in the metrics by which KEF will proceed (see Table 1). These measurements go beyond those in HE-BCI, particularly in the ways in which Public and Community Engagement will be monetized. They offer means of recognizing Engagement that is currently not rewarded through HEIF. While some measurements overlap with REF Research Environment narratives and Impact Case Studies, there is the possibility that responses will be collated and presented differently. Indeed, there is scope for submission of narratives grounded in evidence (UKRI 2019b). These measurements may go beyond those in HE-BCI, particularly in the ways in which Public and Community Engagement will be monetized, and offer means of recognizing Engagement that is currently not rewarded through HEIF. While some measurements overlap with REF Research Environment narratives and Impact Case Studies, there is the possibility that responses will be collated and presented differently. Indeed, there is scope for submission of narratives grounded in evidence (UKRI $2019 b$ ). Even though evaluation takes place at institutional level, it is likely that departmental and faculty narratives will become important in framing and illustrating the broader contribution of institutions.

Table 1. KEF Metrics and Perspectives (see Research England 2020, 7-8)

\begin{tabular}{|l|l|}
\hline Metric & Perspectives \\
\hline Research partnerships & $\begin{array}{l}\text { C Contribution to collaborative research } \\
\text { (cash) as proportion of public funding (HE- } \\
\text { BCI table 1a, minus in-kind contributions) } \\
\bullet \text { Co-authorship with non-academic partners } \\
\text { as a proportion of total outputs (data provider } \\
\text { TBD) }\end{array}$ \\
\hline Working with business & $\begin{array}{l}\text { - Innovate UK income (KTP and grant) as } \\
\text { proportion of research income (Innovate UK) }\end{array}$ \\
& $\begin{array}{l}\text { HE-BCI Contract research income with } \\
\text { non-SME business normalised for institution } \\
\text { size by HEI Income (HE-BCI table 1b) }\end{array}$ \\
\hline
\end{tabular}




\begin{tabular}{|c|c|}
\hline & $\begin{array}{l}\text { - HE-BCI Contract research income with } \\
\text { SME business normalised for institution size } \\
\text { by HEI Income (HE-BCI table 1b) } \\
\text { - HE-BCI Consultancy and facilities \& } \\
\text { equipment income with non-SME business } \\
\text { normalised for institution size by HEI } \\
\text { Income (HE-BCI table 2) } \\
\text { - HE-BCI Consultancy and facilities \& } \\
\text { equipment income with SME business } \\
\text { normalised for institution size by HEI } \\
\text { Income (HE-BCI table 2) }\end{array}$ \\
\hline Working with the public and third sector & $\begin{array}{l}\text { - HE-BCI Contract research income with the } \\
\text { public and third sector normalised for } \\
\text { institution size by HEI Income (HE-BCI } \\
\text { table } 1 \text { b) } \\
\text { - HE-BCI Consultancy and facilities \& } \\
\text { equipment income with the public and third } \\
\text { sector normalised for institution size by HEI } \\
\text { Income (HE-BCI table 2) }\end{array}$ \\
\hline Skills, enterprise and entrepreneurship & $\begin{array}{l}\text { - HE-BCI CPD/CE income normalised for } \\
\text { institution size by HEI Income (HE-BCI } \\
\text { table 2) } \\
\text { - HE-BCI CPD/CE learner days delivered } \\
\text { normalised for institution size by HEI } \\
\text { Income (HE-BCI table 2) } \\
\text { - HE-BCI Graduate start-ups rate by student } \\
\text { FTE (HE-BCI table 2) }\end{array}$ \\
\hline Local growth and regeneration & $\begin{array}{l}\text { - Regeneration and development income } \\
\text { from all sources normalised for institution } \\
\text { size by Income (HE-BCI table 3) } \\
\text { - Additional narrative/contextual } \\
\text { information }\end{array}$ \\
\hline IP and commercialisation & $\begin{array}{l}\text { - Estimated current turnover of all active } \\
\text { firms per active spin-out } \\
\text { - Average external investment per formal } \\
\text { spin-out (HE-BCI table 4) } \\
\text { - Licensing and other IP income as } \\
\text { proportion of research income (HE-BCI table } \\
\text { 4) }\end{array}$ \\
\hline Public and community engagement & $\begin{array}{l}\text { - Provisional score based on self-assessment } \\
\text { developed with NCCPE. Optional } \\
\text { submission to Research England as part of } \\
\text { narrative template to be provided in February } \\
2020 \text {. Additional narrative/contextual } \\
\text { information }\end{array}$ \\
\hline
\end{tabular}

All of this suggests that transformative projects, including those not monetized, have greater scope for recognition in KEF than they did in HE-BCI. Indeed, there is greater concern for formalizing and recognizing non-monetary contributions in kind, which have often formed 
the basis for Engagement in Politics/IR. This may permit internal comparison of performance and incentivize declaration of Engagement activities for promotion or professional development review purposes. Even if the metrics by which the evaluation are conducted do not, at first glance, appear to expand HE-BCI substantively, there will inevitably be increased workload. Indeed, the KEF consultation process and pilot indicate some possible ways in which that workload will expand.

\section{KEF Pilot}

21 English HEIs volunteered and were selected to contribute to a KEF consultation and pilot in 2018/2019. The consultation brought together the participating HEIs across a series of five workshops to examine the proposed KEF in detail. For Research England (2019), 'The successful pilot exercise demonstrated the feasibility of the overall approach' and granted 'detailed insight into the proposed metrics and narrative templates, identifying potential improvements and areas for further exploration'. The notion of upholding 'fair comparison' between institutions was central to the exercise, since it is clear that the different institutions have different foci that lead to different outcomes. Consultation was also an opportunity for Politics/IR and other areas with less ability to exploit commercially their KE to emphasise the importance of considering in-kind contributions and non-commercial Engagement. Without that case's being made, there was serious scope for non-vocational arts and social science departments to be judged against departments in the natural and medical sciences that have greater capacity to secure large-scale grants within institutions. Unfortunately, due to concern over the recording of those contributions, it was determined that only cash submissions would be assessed in the first iteration (UKRI 2020, 10).

The consequence of the consultation was that the pilot proceeded on the basis of clustering institutions. By way of illustration, my institution, Lancaster, will appear within Cluster X. This cluster contains universities with the following characteristics:

- 'Large, high research intensive and broad-discipline universities undertaking a significant amount of world-leading research'

- 'Much of research funded by RCs and gov't bodies; 8.5\% from industry'

- 'Discipline portfolio balanced across STEM and non-STEM with less or no clinical medicine activity'

- 'Large proportion of taught postgraduates in student population' (Research England 2018c, 16)

The other members of Cluster X are Bath, Birkbeck, Brunel, Durham, East Anglia, Essex, Exeter, Hull, Keele, Kent, Leicester, LSE, Loughborough, Reading, Royal Holloway, SOAS, Surrey, Sussex and York (Research England 2018c, 16-17). Clearly, these are still very different institutions and the outcome of evaluation will always result from remaining differences in foci and location as well as performance. However, for McAlpine (2019), this is

An opportunity for small but specialist universities to showcase their particular strengths. Further, we are intending to bring together this information in a single, consistent, easy to use format, with no more emphasis given to the performance of UCL than a small, specialist arts institution.

While the eventual rating system has not been confirmed, there is some suggestion that submissions will be allocated bands as with TEF (Pells 2017).

Again, although this indicates that the overall burden of data collection will be less onerous than REF, the impetus for internal advancement of Engagement is surely a stimulus 
for administration. This, though, may be minimized through careful consideration of the ways in which Engagement can be pursued.

Research: understanding the relationship between Engagement and Impact

Despite attempts at asserting equivalence with teaching and scholarship, it is clear that the most important element of an academic career for the purposes of progression is research. Given the increasing value of REF Impact Case Studies and Research Environment to REF outcomes, it is vital to understand the relationship between Engagement and Impact. In this light, the UKRI (2019a) has identified two distinct forms of 'impact':

- Academic impact is the demonstrable contribution that excellent research makes to scientific advances, across and within disciplines, including significant advances in understanding, method, theory and application.

- Economic and societal impact is the demonstrable contribution that excellent research makes to society and the economy, of benefit to individuals, organisations and nations.

For REF purposes, concern lies with 'Economic and societal impact', which is defined as 'an effect on, change or benefit to the economy, society, culture, public policy or services, health, the environment or quality of life, beyond academia'. It 'includes, but is not limited to, an effect on, change or benefit to':

- the activity, attitude, awareness, behaviour, capacity, opportunity, performance, policy, practice, process or understanding

- of an audience, beneficiary, community, constituency, organisation or individuals

- in any geographic location whether locally, regionally, nationally or internationally....

- the reduction or prevention of harm, risk, cost or other negative effects. (REF 2021 $2019,69)$

Importantly, while impact on research is excluded, impact 'on students, teaching or other activities both within and beyond the submitting HEI are included' (REF 2021 2019, 68). The latter form of impact occurs through transformative work on methods and approaches to pedagogy, especially where this takes place across the sector. That might often be overlooked in such fields as Politics/IR, since the Impact may seem to lie within the remit of Educational Research. However, there are many examples of pedagogical work, particularly with regard to employability and Widening Participation (see AFAO 2018), that foster change in practice across the sector.

Beyond this broad definition of Impact, it is clear that UKRI regards it as being advanced in many ways: 'through creating and sharing new knowledge and innovation; inventing ground-breaking new products, companies and jobs; developing new and improving existing public services and policy', and 'enhancing quality of life and health' (UKRI 2019a). In this respect, by constituting a relationship between academic and non-academic, Engagement is a pathway to KE and, potentially, to Impact. However, while Research Impact often stems from engagement with research users (an example of an exception is provided below), not all engagement leads to Research Impact for REF. This is, firstly, because research impact is seen to stem directly from original peer-reviewed research rated at $2^{*}$ quality in the REF. For this reason, because engagement often consists of building relationships with potential collaborators and does not always lead to transformation of behaviour as a consequence of research findings, it may not always foster relevant impact, even if the formation of relationships themselves is impactful on a personal level. Indeed, it is possible for 
a great deal of engagement to be conducted without its being based on research. Examples include outreach work with schools that does not lead to changes in school policy and student outlook as well as participation in the organizational life of charities unrelated to an academic's field of research.

In one respect, this means that a great deal of energy can be expended without recognition within the REF. While KEF's quantitative focus may lead to an undifferentiated appraisal of Engagement, it is likely that Engagement that stems from research might be regarded more highly by KEF (not least because it may be more exploitable commercially) and, at least, provide the basis for a clearer narrative in establishing the nature, purpose and outcome of activities and programmes. While the data required for KEF might overlap with both REF Impact Case Studies and REF Research Environment narratives, it is likely to capture more forms of Engagement than are currently noted and to provide more specific and detailed references to activities than that outlined in the REF Research Environment narrative. It is also possible that Engagement can enhance research quality by virtue of access to particularly valuable data and provision of pathways to impact by virtue of the formation of relationships.

It is important that a linear account of the relationship between research, engagement and impact is established. The clearest illustration is provided by Vertigo Ventures' $(2012,11)$ model.

Inputs (Time and material resources, e.g. grants) lead to Outputs (Research activities e.g. research papers and presentations) lead to Activities (Translation activities, e.g. inclusion in Government white paper) lead to Outcomes (changes that happen e.g. change in understanding) lead to Impact (Measurable change that occurs, e.g. change in the volume of sales of a product)

Engagement may take place during production of outputs as well as activities. Particularly in cases involving ethnographic or participatory methods, Engagement is both central to production of research outputs and to research impact, with the same or related groups being involved in the research and impact phases. These activities may be targeted and planned, but they may also be serendipitous, such that non-academics come to understand the relevance of research independently of engagement and deploy the findings themselves. Indeed, it is quite possible for impact to be achieved many years after the death of the author (see Rowlett 2015, 2). For example, it is possible for TV companies to use research findings on historical events to inform documentaries that then inform viewers with a particular interest in the specific content of the programmes who then go on to alter their behaviour as a consequence. However, insofar as it constitutes an active form of lobbying, Engagement may increase the likelihood of outcomes and attendant Impact, especially where it comes to shape organizational practice. In this regard, Engagement is facilitative of Impact and, in order that it be efficient, it is prudent for academics to devise strategies to ensure that Impact is the end product. Indeed, if shaped effectively, Engagement ought to provide academics with the relationships by which to develop an evidential basis for asserting REF qualifying Impact through qualitative and quantitative research. This then provides the platform for further Impact activities via Engagement and for further research, since the data may strengthen subsequent outputs.

While it is important to emphasise that colleagues will report contrasting routes to impact, there may be some basic principles that facilitate Engagement, including the need for clarity in communication of findings and effective targeting with specific groups. For academic colleagues, it is absolutely essential that there is clear conceptualisation and articulation of the stages, collection and description of the evidence indicating impact: 
Since REF2014 best practice within the sector has been developing and some HEIs now gather both evidence of the impact itself and also indicators of translational activities, which itself can be used as evidence of the impact pathway followed and thereby more effectively link the impact with the original, underpinning research.... Panel chairs were clear that the narrative and the impact evidence needed to show distinctly the difference between the activities and impact. Doing this well helps with attribution and encourages behaviour that enables activities which create opportunities for impact such as industry outreach events. (Vertigo Ventures 2016, 11)

The sector is recognizing this through the emergence of Impact funding. For example, in 2019, Lancaster (2019b) was awarded an ESRC Impact Acceleration grant of £1m over 4 years. This will fund collaborative projects that fall $51 \%$ and above within the ESRC remit. The focus on Impact reflects, again, the increasing sense of research having to demonstrate external value. However, that value remains open to interpretation by individual academics, granting scope for transformative, critical work, and providing the basis for enhancement of other aspects of the profession.

\section{Contracts and consultancy: formalising Engagement}

One important consideration in managing the various elements of unpredictability in Engagement is the way in which relationships can be formalized, since a great deal of activity is presently conducted outside of contractual contexts. In many cases, academics provide pro bono services to non-academic partners. In some instances, reciprocal services can be offered by non-academic partners, not simply with regard to planning, development and dissemination of research, but also in relation to teaching. These types of agreements have led to contributions to my own teaching (see Johnson, Gallagher and Appleton 2019). They are, though, often informal and there are serious attendant risks in terms of reliability, performance and fulfilment.

Interestingly, even those relationships that constitute in-kind exchanges can be recognized within a binding contract, since, legally, payment can consist of anything of value to the other party and that value is not defined. While formalizing arrangements may add pressure to an otherwise informal and volitional relationship, there may be good reasons for grounding exchange within a contract. This is especially true in those circumstances in which the failure of non-academic partners to fulfil commitments is likely to have a significantly detrimental effect on teaching or other activities. In such instances, judgements on whether to formalize an arrangement will depend upon the approximate value concerned, the effect on the relationship and expectations of the parties and the duration of the relationship. Whereas low value, short-term KE relationships may not warrant a contract, given the transaction cost of putting one in place, higher value, longer-term relationships may often benefit from a simple contract capturing mutual obligation and clarifying issues such as insurance and liability.

This is clearly important for two reasons. Firstly, the Cambridge Analytica scandal highlights the extent to which activities that are not clearly circumscribed by professional ethics can inflict damage on institutions. Secondly, the amount of Engagement activity will likely increase as a result of growing interest among businesses and other organisations in procuring the services of individual academics. That all suggests that the quality and quantity of Engagement is to change and, in a litigious society, there are prudential reasons for contracts.

One means of formalizing Engagement is through Consultancy, which

is the provision of expert advice based on existing knowledge. Unlike research, the purpose of undertaking consultancy is not to create new original knowledge, although 
new information based on the application of expertise to a client's challenge or problem may result from the work. (Lancaster University 2019c)

This is a means of making clear academic colleagues' responsibilities and entitlements and setting out a framework with regard to resources to be drawn upon in fulfilment of contracts (see Marshall and Reid 2018; Anderson 2018).

Demand for Consultancy is indicated by services such as konfer, which was co-created by the National Centre for Universities and Business (NCUB) and UK Research and Innovation (UKRI) to serve as an 'innovation brokerage' service to open up 'research, researchers and services in UK universities and research institutions' to business and other non-academic actors, and 'impact partners' for academics. 'It harvests data from multiple sources', including 'University web pages, RSS News Feeds, Gateway to Research (GtR), REF Case Studies, ORCiD, Equipment.data.ac.uk, Video (YouTube), and Latest funding opportunities from Innovate UK' (konfer 2019). Because of the importance of income generation to the HE-BCI survey, there is increasing concern among institutions for promoting such arrangements. Indeed, as KEF is likely to record contributions in-kind, Consultancy serves as a useful mechanism of attributing a measurable value to all forms of Engagement. It also ensures declaration of funds that may not previously have been declared to the university or, indeed, the tax authorities. This means both that income is recorded efficiently and that academics can fulfil tax obligations without the need for Self-assessment submissions. There are different arrangements at different institutions, but declaration of income is generally encouraged by not imposing a transaction cost and by offering the possibility of funds being allocated to a Personal Research Account that automatically rolls over across financial years without the possibility of being absorbed by the university (Lancaster University 2019c).

\section{Discussion}

It is important, in light of this conceptual analysis to consider strategic means of advancing the interests of departments. If there is a metaethics of Engagement articulated in the material examined above, it is that Engagement is good and that there should be more of it. This provides great scope for transformative projects that go beyond anything neoliberal policy makers might have in mind. As Selby (2018) has compellingly argued with regard to IR and the Impact agenda, there is great scope for critical action. For example, the primary mode of praxis for Trotskyists is the creation and development of counter-hegemonic structures. This depends upon Engagement with a range of non-academic actors in various sectors. In effect and in this context, Engagement provides a legitimate space within which to pursue class war. Academics, as part of their paid workload, can develop counter-hegemonic structures grounded in their research, advance class consciousness and pursue political action that undermines neoliberalism itself. Indeed, if the transformation is significant, the academic may then be rewarded with a REF Impact Case Study worth several hundred thousand pounds to their department. If we are talking about the internal contradictions of neoliberalism, this must surely be a good example. But beyond any perceived opportunity for transformation, the need for strategy is highlighted by perhaps the key concern raised by institutions in Universities UK's $(2020,10)$ summary of consultation outcomes on the KE Concordat: that the Concordat evaluation will clash with REF, KEF,

the review of the Higher Education Statistics Agency's (HESA) Higher Education Business and Community Interaction survey (HE-BCI), much of which under current plans will inform the use of metrics in the KEF. 
This does present a picture of a sector embedded in Shore and Wright's (2000) account of an audit culture and moving toward Ginsberg's (2015) all administrative university.

In that light, it is essential that academics develop strategy to maximise the elements that have historically distinguished work in the profession from labour in other fields, such as intellectual autonomy. That autonomy is sustained through maximisation of time for activities that individual academics regard as valuable, especially those with transformative impact, by fulfilling institutional and statutory responsibilities as efficiently as possible. Given the structural pressures at play, strategy must lie in deploying Engagement as an 'upstream intervention' to promote the quality of teaching and research and ensure that work satisfies the requirements of KEF, REF and TEF. The account of the relationship between Engagement and Impact necessarily indicates logical pathways, but colleagues may not have actively integrated Engagement into teaching in a way that creates a cycle of action from research through Engagement to teaching. Doing that serves as a central element of Engagement strategy and is an essential means of pedagogical enhancement.

\section{Teaching}

There have been two contrasting stimuli for reconsideration of the value of KE from Engagement to teaching: i) Government concern for skills development; ii) activist concern for development of new, and epistemological challenges to privileged, knowledge forms. While it is clear that the likes of Guest (2019) have in mind the former, there is a rich tradition of participatory contributions to teaching (see Johnson, Gallagher and Appleton 2019). Among other forms, non-academic contribution to teaching can include guest lectures, seminars or workshop facilitation, participation in discussions and debates, hosting of placements, codevelopment of teaching materials and contribution to audio-visual materials. Such engagement can add richness to content, demonstrate the real-world implications and applications of ideas, foster opportunities for students to engage with non-academic groups and create links, and develop the capacity to communicate subject-specific ideas, with nonacademic groups (see Walkington 2015).

This is particularly important pedagogically, since Engagement can be viewed through the lens of research-informed teaching. This consists of four distinct forms, of which three can clearly be supported through engagement (see HEA 2017):

- Research-led teaching denotes teaching grounded in the academic's recent or ongoing research. Engagement with non-academic participants or collaborators offers means of making that research more tangible and of presenting teaching as being of specific or exclusive value.

- Research-oriented teaching denotes teaching of research methods and processes. Engagement with practitioners offers means of explaining the real-world application and experience of methods and processes and, specifically with regard to participatory, ethnographic or other qualitative approaches, of developing with students means of advancing those processes and methods

- Research-based learning denotes teaching in which students learn as researchers. Engagement is the clear means of presenting students with opportunities to conduct research in controlled and ethically circumscribed circumstances.

Instrumentally, research-informed teaching is presented as a means of enhancing employability by fostering transferable skills (Russell Group 2009; 2017, 3) and engagement with nonacademic groups may give students, particularly in non-vocational subjects and disciplines, a sense that their study is tangible and relevant to work. Given that perceived effect on employability is a key factor in NSS scores (see Lenton 2015, discussion on p. 123), there are 
good reasons to take this seriously. Even then, Engagement in teaching need not simply be viewed through the lens of employer engagement (see discussion in Kettle 2013) - students may perceive benefit in engagement with non-academic groups even where there is little direct concern for postgraduate employment. While more research needs to be conducted on this area, it is clear that research-informed teaching, with increasing engagement with non-academic groups, is presented as being associated with Russell Group institutions (see Russell Group 2009; 2017). More substantively, there are many instances in which the participation of nonacademics is of intrinsic value, including with regard to diversifying and adding depth to curricula (see NUS 2015), which is a truly transformative endeavour. Moreover, in my own discipline, Politics/IR, there are some topics that can only be examined through Engagement with non-academics, such as policy makers.

However, embedding engagement in the curriculum depends upon adoption of pedagogical flexibility and creation of structures to ensure that the contribution of nonacademic partners is focused and targeted on specific learning outcomes (see Kettle 2013). While there are means of tailoring work to maximise outcomes by identifying specific contexts in which Engagement can aid teaching, there are many good reasons not to embed engagement in curricula. These include difficulty in managing contributors, assuring the quality of contributions and assessing student work in light of differing experiences of Engagement with non-academic partners. Indeed, given that student satisfaction is affected strongly by the extent to which teaching is perceived to be well-organised and smoothly run (see Burgess, Senior and Moores 2018, 10), embedding Engagement is risky. This is particularly true in final year, in which the impact of engagement may be greatest both with regard to employability and to student satisfaction. As such, it may be that providing extra-curricula forms of Engagement are preferable in various circumstances. Such forms include voluntary research institute internships and research placements, as well as Knowledge Transfer Partnerships (see NCUB 2013) with the private sector, which can be seen as being specifically valuable in terms of advancing employability where opportunities for student participation are built into agreements. Indeed, there is some evidence to suggest that such voluntary arrangements are especially valued by 'women, younger students and students from less advantaged backgrounds who are more motivated to volunteer to enhance their employability' (Brewis, Russell and Holdsworth 2013, vii-viii). Guidance on such work is available from a number of sources, including NCCPE (2018). While that all raises questions over the acceptability of students viewing extra-curricular activities as means of compensating for disadvantage, it also suggests that there are means of departments providing support in ways that do not undermine curricula cohesion and student confidence.

\section{Achieving efficiency through Engagement cycles}

There are many different means of including engagement within a research and teaching framework. Given that Engagement imposes opportunity cost, it is essential that efficiency be achieved through effective shaping and ordering of activities. In light of the concerns above, there are two cyclical processes that ensure that research is eligible for REF Impact Case Study and Environment inclusion and enable engagement to contribute to teaching and the TEF:

Case 1

1) Academic identifies research need

2) Academic publishes Peer-reviewed article of potential relevance to non-academic group/s

3) Academic publishes op-ed piece, placed with the support of the Press Office, that outlines the core findings from the article in language and in a publication accessible to the non-academic group 
4) Academic makes Initial contact with non-academic group using op-ed as reference point

5) Academic and non-academic group engage in discussion about application of research findings

6) Parties formalise agreement about nature and extent of engagement through consultancy agreement

7) Parties co-develop policy with for deployment by non-academic user for benefit of beneficiaries

8) Academic records impact of engagement

9) Non-academic group contributes to delivery of undergraduate module with contribution allocated an in-kind monetary value

Case 2

1) Academic accepts offer of contracted research or consultancy from non-academic funder/user

2) Academic produces research requested by non-academic funder/user

3) Academic publishes research in report for non-academic funder/user

4) Academic develops research into peer-reviewed publication

5) Non-academic funder/user takes up findings and develops policies for their organisation

6) Academic records impact of engagement

7) Non-academic funder/user provides contribution to academic's teaching

Whether Engagement is advanced for instrumental or transformative ends, efficiency is valuable. While the ideal outcome is enrichment of research, achievement of REF Impact and enhancement of teaching, the shaping and ordering of activities in such forms ensures that, even if subsequent activities fail, the opportunity cost is limited. Seeing activities as cyclical is important in integrating elements of workload and ensuring maximum value as a consequence. To return to the broader concern for transformative possibility, academics engaging in the creation of counter-hegemonic structures benefit from their efficient and effective development as much as those aiming for commercial exploitation.

\section{Conclusion}

The work above serves to conceptualize and differentiate a series of related concepts. The fact that those concepts are often elided and that colleagues regularly express confusion over demands for fulfilment of agendas such as Engagement reflects the way in which neoliberal rolling back of the state necessarily complicates pursuit of ends by different professions and sectors. That ought not, though, to dissuade colleagues from Engagement, since it offers genuine scope for transformative impact and, to be clear, there are few professions in which employees can be paid, for example, for attempting to overthrow capitalism. It is vital, though, that colleagues are clear about what Engagement entails and how and why they ought to organize their work, since, irrespective of intentions, this is activity that can serve seriously to detract from fulfilment of other professional and personal responsibilities. The guidance above should, at the very least, ensure that academics can develop efficient and effective strategies by which to Engage in their own disciplines.

\section{References}

Anderson F. 2018. "KEF - A Useful Framework or Another Restriction?." VWV Online, March 16. https://www.vwv.co.uk/news-and-events/blog/higher-education-law/kef-a-usefulframework-or-another-restriction. 
Berry, M. 2014 "Neoliberalism and the City." Housing, Theory and Society 31: 1-18.

Brabner, R. 2019. "Leading universities pledge commitment to local communities." UPP, February 11. https://upp-foundation.org/leading-universities-pledge-commitment-tolocal-communities.

Brewis, G., Russell, J. and Holdsworth, C. 2010. Bursting the Bubble: Students, Volunteering and the Community. London: Institute for Volunteering Research.

Burgess, A., Senior, C. and Moores, E. 2018. "A 10-year case study on the changing determinants of university student satisfaction in the UK." PLoS ONE, 132: e0192976. doi:10.1371/journal.pone.0192976.

Coates-Ulrichsen, T. 2018. Knowledge Exchange Framework Metrics: A Cluster Analysis of Higher Education Institutions. Bristol: Research England.

Collini, S. 2012. What are Universities for? London: Penguin.

De Boer, H., J. Enders, and U. Schimank. 2007. "On the Way Towards New Public Management?" In New Forms of Governance in Research Organizations, edited by D. Jansen, 137-52. Dordrecht: Springer.

Denscombe, M. 2010. The Good Research Guide. Maidenhead: Open University Press.

Edwards, A. and Talbot, R. 1994. The Hard-pressed Researcher. London: Longman.

Ginsberg, B. 2011. The Fall of the Faculty. New York: OUP.

Guest, M. 2019. "Recognising teaching in knowledge exchange." WONKHE, August 19. https://wonkhe.com/blogs/recognising-teaching-in-knowledge-exchange.

GuildHE. 2018. Practice-Informed Learning: The Rise of the Dual Professional. London: GuildHE.

HEA. 2017. What does Research-Informed Teaching look like? York: HEA.

Higher Education and Research Act. 2017. c.29. London: The Stationery Office.

Ishkanian, A. and Glasius, M. 2018. "Resisting neoliberalism?" Critical Social Policy 38 (3): 527-546.

Johnson, M. 2016. "Communicating politics: active learning and integrating entry, teaching and exit strategies." British Journal of Educational Studies, 64 (3): 315-335.

Johnson, M., Danvers, E., Hinton-Smith, T., Atkinson, K., Bowden, G., Foster, John, Garner, K. et al. 2019. "Higher Education Outreach." British Journal of Educational Studies, 67 (4): 469-491.

Johnson, M., Gallagher, V. and Appleton, A. 2019. "Teaching Participatory Action Research: Fostering Impact." Journal of Political Science Education, doi:10.1080/15512169.2019.1616551.

Kettle, J. 2013. Flexible pedagogies. York: HEA.

Kilburn, D., Nind, M. and Wiles, R. 2014. "Learning as Researchers and Teachers." British Journal of Educational Studies, 622: 191-207.

konfer 2019 "About konfer." konfer. Accessed 30 October. https://konfer.online/about.

Lancaster University. 2019. "Consultancy." Lancaster University. Accessed 21 October. https://www.lancaster.ac.uk/research/research-enterprise-services/consultancy.

Lewthwaite, S. and Nind, M. 2016. "Teaching Research Methods in the Social Sciences." British Journal of Educational Studies 644: 413-430

McAlpine, H. 2019. "What do businesses think about the KEF? II." NCUB. Accessed 30 October. http://www.ncub.co.uk/blog/what-do-businesses-think-about-the-kef-ii.

Lenton, P. 2015. "Determining student satisfaction." Economics of Education Review 47: 118127.

Mann, B. L. 2006. "Case Study Research and Online Learning”. In Case Study Research on Web-Based Learning, edited by B. L. Mann, 70-79. London: Information Science Publishing. 
Marshall, J. and Reid, G. 2018. "Value in a Knowledge Exchange Framework." National Centre for Universities and Business. July. http://www.ncub.co.uk/blog/value-in-aknowledge-exchange-framework.

McFarlane-Dick, D. and Roy, A. 2006. Enhancing Student Employability. Gloucester: Quality Assurance Agency for Higher Education.

McMillan Group. 2016. University Knowledge Exchange KE Framework: good practice in technology transfer, Bristol: HEFCE.

NCCPE. 2018. Working with Students. Bristol: NCCPE.

NCCPE. 2019. "What is public engagement." NCCPE. Bristol: NCCPE.

NCUB. 2013. Knowledge Transfer Partnerships. London: NCUB.

Niskanen, W. A. 1994. Bureaucracy and Public Economics. London: Elgar.

NUS. 2015. Liberation, Equality, and Diversity in the Curriculum. London: NUS.

OfS and UKRI. 2018. Collaboration Agreement between The Office for Students OfS and UK Research and Innovation. London: OfS.

Pells, R. 2017. "Knowledge exchange framework to band universities by performance." THES.

December 1. https://www.timeshighereducation.com/news/knowledge-exchangeframework-band-universities-performance.

PraxisAURIL. 2018. "Knowledge Exchange Framework KEF." PraxisAuril. Accessed 28 November. https://www.praxisauril.org.uk/content-category/knowledge-exchangeframework-kef.

Reid, G. 2019 "What do businesses think about the KEF? I." NCUB. Accessed 30 October. http://www.ncub.co.uk/blog/what-do-businesses-think-about-the-kef-

i?utm_source=Weekly+Member+Update\&utm_campaign=a9ad0f2414-

EMAIL_CAMPAIGN_2019_12_JULY\&utm_medium=email\&utm_term=0_5f44acb b9f-a9ad0f2414-334402373.

REF 2021. 2019. Guidance on Submissions, Bristol: REF 2021.

Research England. 2018a. "Knowledge Exchange Framework." Research England. Accessed 28 November. https://re.ukri.org/knowledge-exchange/knowledge-exchangeframework/.

Research England. 2018b. Summary of KEF call for evidence responses. Bristol: Research England.

Research England. 2018c. Knowledge Exchange: Framework Consultation. Bristol: Research England.

Research England. 2019. Knowledge Exchange Framework: Outcomes of Consultation and Pilot Exercise. Bristol: Research England.

Research England. 2020. Knowledge Exchange Framework: Decisions for the first iteration, Bristol: Research England.

Rowlett, P. 2015. "“The unplanned impact of mathematics" and its implications for research funding." BSHM Bulletin: Journal of the British Society for the History of Mathematics 301: 67-74.

Russell Group. 2009. Research-led learning. London: Russell Group.

Russell Group. 2017. Benefits of the research-intensive learning environment at Russell Group universities. London: Russell Group.

Sayer, D. 2015. Rank hypocrisies: the insult of the REF. London: Sage.

Selby, J. 2018. "Critical international relations and the impact agenda." British Politics 13: 332-347.

Shore, C., and S. Wright. 2000. "Coercive Accountability: The Rise of Audit Culture in Higher Education.” In Audit Cultures, edited by M. Strathern, 57-89. London: Routledge.

Skidmore, C. 2019. Letter to David Sweeney. 2 October.

Spicer, A. 2017. Business Bullshit. London: Routledge. 
Stake, R. E. 1995. The Art of Case Study Research. London: Sage.

Susman, G. I. and Evered, R. D. 1978. "An Assessment of the Scientific Merits of Action Research.” Administrative Science Quarterly 234: 582-603.

UKRI. 2019a. "Excellence with Impact." UKRI. Accessed 28 October. https://www.ukri.org/innovation/excellence-with-impact/.

UKRI. 2019b. "FAQs relating to the Ministerial announcements on 26 September 2019, at the Research England Engagement Forum." UKRI. Accessed 05 November. https://re.ukri.org/documents/2019/faqs-ministerial-announcements-engagementforum.

Universities UK. 2019. Concordat for the Advancement of Knowledge Exchange in Higher Education England. London: Universities UK.

Universities UK. 2020. Knowledge Exchange Concordat: Summary of Consultation Outcomes. London: Universities UK.

UPP. 2019. Truly Civic. London: UPP.

Vertigo Ventures. 2016. Collecting Research Impact Evidence: Best Practice Guidance for the Research Community. Bristol: HEFCE.

Vitae. 2019. "Knowledge Exchange." Vitae. Accessed 30 October. https://www.vitae.ac.uk/doing-research/leadership-development-for-principalinvestigators-pis/intellectual-leadership/demonstrating-research-impact/knowledgeexchange.

Wade, G. 2017. "Does university knowledge exchange need a framework?" Universities UK, October 13. https://www.universitiesuk.ac.uk/blog/Pages/Does-UniversityKnowledge-Exchange-need-a-Framework.aspx.

Walkington, H. 2015. Students as researchers. York: Higher Education Academy.

Watermeyer, R. and Chubb, J. 2019. "Evaluating 'impact' in the UK"s Research Excellence Framework REF." Studies in Higher Education 449: 1554-1566

Watermeyer, R. and Lewis, J. 2018. "Institutionalizing public engagement through research in UK universities: Perceptions, predictions and paradoxes concerning the state of the art." Studies in Higher Education, 439: 1612-1624.

Wilson, P., Woolger, A. and Dodd, M. 2017. Students: Experience, Engagement and Communities, Leeds: York Consulting.

Yin, R. K. 1984. Case Study Research. Newbury Park: Sage. 